$\mathrm{p}=0.014)$ and increased tenosynovial volume $(\mathrm{B}=7.39,95 \% \mathrm{Cl} 0.41 \sim 14.38$, $\mathrm{p}=0.039$ ) (Table).

Table 1 Univariate and multivariate analysis for factors associated with synovial volume and tenosynovitis volume at baseline in all ERA patients

Table Univariate and multivariate analysis for factors associated with synovial volume and tenosynovitis volume at baseline in all ERA patients

\begin{tabular}{|c|c|c|c|c|c|c|}
\hline \multicolumn{7}{|c|}{ Synovial volume } \\
\hline & \multicolumn{3}{|c|}{ Univariate } & \multicolumn{3}{|c|}{ Multivariate } \\
\hline & B & $95 \% \mathrm{CI}$ & $P$ value & B & $95 \% \mathrm{CI}$ & $P$ value \\
\hline Age & 0.79 & $0.09-1.50$ & 0.026 & & & \\
\hline Sex & 0.23 & $\cdot 0.043 \cdot 0.51$ & 0.098 & & & \\
\hline $\mathrm{Dj}$ & 6.58 & $1.53-11.64$ & 0.011 & & & \\
\hline DAS28.CRP & 14.22 & $5.25-23.18$ & 0.002 & & & \\
\hline miR-99b-5p & 16.15 & $2.98 \sim 29.32$ & 0.018 & 15.65 & $3.42 \sim 27.89$ & 0.014 \\
\hline
\end{tabular}

Dj: damage joint count; DAS 28: Disease Activity Score 28

\begin{tabular}{|c|c|c|c|c|c|c|}
\hline \multicolumn{7}{|c|}{ Tenosynoxial volume } \\
\hline & \multicolumn{3}{|c|}{ Univariate } & \multicolumn{3}{|c|}{ Multivariate } \\
\hline & B & $95 \% \mathrm{CI}$ & $P$ value & B & $95 \% \mathrm{CI}$ & $P$ value \\
\hline Age & 0.51 & $0.10 \cdot 0.92$ & 0.016 & & & \\
\hline Sex & 0.47 & $-0.07-0.94$ & 0.054 & & & \\
\hline $\mathrm{Tj}$ & 1.07 & $0.044-2.10$ & 0.042 & & & \\
\hline DAS28.CRP & 5.86 & $0.42-11.30$ & 0.035 & & & \\
\hline miR-99b-5p & 7.36 & $-10.05 \sim 13.71$ & 0.025 & 7.39 & $0.41 \sim 14.38$ & 0.039 \\
\hline
\end{tabular}

Tj: Tender joint count; DAS 28: Disease Activity Score 28

Conclusions: Increased cell-free circulating miR-99b-5p is associated with increased synovial and tenosynovial volume as well as more severe bone erosion in ERA patients at presentation. Whether it may serve as a biomarker for monitoring the progression of synovitis and damage would need to be addressed in prospective studies

Acknowledgements: This study was partly supported by the Health and Medical Research Fund (project no 10110071).

Disclosure of Interest: None declared

DOI: 10.1136/annrheumdis-2018-eular.3293

\section{SAT0657 MICROWAVE RADIOMETRY-DERIVED THERMAL CHANGES OF SACROILIAC JOINTS AS A BIOMARKER OF SACROILIITIS IN PATIENTS WITH SPONDYLOARTHROPATHY}

K. Laskari, D.A. Pitsilka, G. Pentazos, E. Siores, M.G. Tektonidou, P.P. Sfikakis. Rheumatology Unit, 1st Dept. Of Propaedeutic Internal Medicine, Athens University Medical School, Athens, Greece

Background: Microwave Radiometry (MR) is a rapid, easy-to-perform, non-invasive method that detects in-depth tissue temperatures. In a proof-of-concept study we found that an increased knee joint temperature detected by MR reflects the presence of subclinical synovial inflammation in patients with rheumatoid arthritis. $^{1}$

Objectives: To test the hypothesis that MR-derived increased temperature of sacroiliac (SI) joints is a biomarker of local inflammation in patients with axial spondyloarthritis (SpA) in a cross-sectional study.

Methods: Sixty patients with SpA (32 with ankylosing spondylitis, 24 with psoriatic arthritis, 4 with enteropathic arthritis) underwent clinical and laboratory assessments, magnetic resonance, $\mathrm{X}$-ray imaging, and MR measurements of SI joints. All MR measurements were performed by a physician who was blinded to the clinical evaluations. Patients were classified as having active sacroiliitis (pain and/or tenderness and/or bone marrow oedema on magnetic resonance, $n=23$ ), inactive sacroiliitis $(n=19)$, whereas signs/symptoms of a present/past SI joint involvement were absent in the remaining 18 patients. Twenty five age-matched healthy individuals served as controls. Three MR measurements were performed along each SI joint and a number was calculated for each patient denoting the difference $(\Delta T)$ in temperature between the warmest point in either SI joint and a control point, which was the iliac bone.

Results: A lower $\Delta T$, indicative of a warmer joint, was found in patients with either active or inactive sacroiliitis compared to patients without sacroilitis [mean (SD) $\Delta \mathrm{T}$ of $0.1(0.5)$ vs. $0.6(0.5)$, respectively, $\mathrm{p}=0.001$ ] or healthy controls [mean (SD)
$\Delta \mathrm{T}$ of $0.60(0.55), \mathrm{p}=0.003$ ]. A warmer $\mathrm{SI}$ joint was not significantly associated with the presence of local tenderness or pain, the patient visualised analogue pain scale for SI joints, the BASDAI score, the New York radiological grading of SI lesions, or C-reactive protein levels. Notably, all 20 patients with increased SI joint temperature $(\Delta T<0.05$, which was the mean $\Delta T$ value minus one $S D$ in healthy controls) had either symptoms/signs of sacroiliitis or imaging confirmed sacroiliitis even in the absence of clinical findings. Receiver operating analysis showed that a $\Delta T$ cut-off of 0.35 could discriminate with a sensitivity of $78 \%$ and specificity of $74 \%$ patients with sacroiliitis from those without, or from healthy controls (both $\mathrm{p}=0.001$ ); sensitivity reached $100 \%$ for $\Delta T$ values equal or lower than 0.05 .

Conclusions: MR-derived increased in-depth temperature indicative of local inflammation of $\mathrm{SI}$ joints may serve as an additional diagnostic marker in axial SpA

\section{REFERENCE:}

[1] Zampeli El, et al. "Detection of subclinical synovial inflammation by microwave radiometry," PLoS ONE 2013 May;8(5):e64606.

Disclosure of Interest: None declared DOI: 10.1136/annrheumdis-2018-eular.6564

\section{SAT0658 QUANTITATIVE ANALYSIS OF JOINT STRUCTURE BY HR-PQCT IN PATIENTS WITH RHEUMATOID ARTHRITIS: CORRELATION BETWEEN CARTILAGE LOSS AND BONE DETERIORATION}

K. Chiba ${ }^{1}$, N. Imamoto ${ }^{2}$, N. Oki ${ }^{3}$, K. Watanabe ${ }^{1}$, M. Osaki ${ }^{1}$, A. Kawakami ${ }^{2}$. ${ }^{1}$ Department of Orthopedic Surgery; ${ }^{2}$ Department of Immunology and Rheumatology, ${ }^{3}$ Department of Radiological Sciences, Nagasaki University, Nagasaki, Japan

Background: HR-pQCT is a high-resolution CT dedicated to human extremities. It has been used for the study of rheumatoid arthritis (RA) in recent years, enabling quantitative analysis of bone erosion, bone microstructure, and joint space.

Objectives: The purpose of this study is to investigate a correlation between cartilage loss and bone deterioration (juxta-articular osteoporosis and erosion) in patients with RA by HR-pQCT.

Methods: Twenty patients with RA ( $70 \pm 8$ years, 15 female, 5 male) participated in this study. The second and third MCP joints were scanned by second-generation HR-pQCT (XtremeCT II, Scanco Medical, Switzerland) at the voxel size of $61 \mu \mathrm{m}$.

The following parameters were measured semiautomatically using dedicated software (TRI/3D-BON, Ratoc System Engineering, Tokyo) based on previous studies $^{1-3}$. 1) Average joint space width (ave-JSW) of MCP joints, 2) bone microstructure of metacarpal head: volumetric bone mineral density (vBMD), trabecular thickness (Tb.Th), trabecular number (Tb.N), and structure model index (SMI), 3) total volume of erosions (ER-volume) on the metacarpal head.

Results: Ave-JSW of MCP joints was 1.47 (1.00-1.89) mm. vBMD of the metacarpal head was $131.4(54.3-263.5) \mathrm{mg} / \mathrm{cm}^{3}$, Tb. Th was $213.1(166-329.3) \mathrm{mm}$, Tb.N was $0.95(0.69-1.50) / \mathrm{mm}$, and SMI was $1.68(0.65-2.52)$. The total number of erosions was 31, and an average number of erosions on each metacarpal head was 0.9 (0-4). Total ER-volume on the metacarpal head was $1.96(0-16.7) \mathrm{mm}^{3}$. Ave-JSW had significant correlations with vBMD, SMI and ER-volume ( $R=0.37,-$ $0,40,-0.42, p<0.05)$.
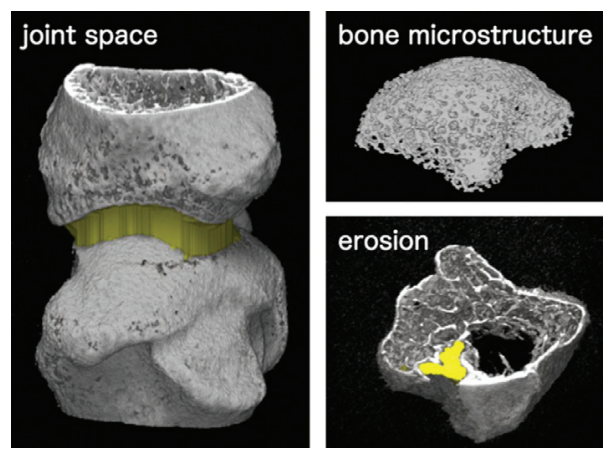

Conclusions: Cartilage loss was correlated with juxta-articular osteoporosis and bone erosion in RA patients. Quantitative evaluation of total joint structure (joint space, bone microstructure, and erosion) by HR-pQCT would be useful for the pathophysiological research and drug development of RA.

\section{REFERENCES:}

[1] Burghardt AJ, et al. Ann Biomed Eng 2013. 